\section{Conclusions}

True global planarization over diverse patterns is not likely to be achieved by spin application of an organic film followed by etchback, at least with materials common to the semiconductor industry. There exists a limiting pattern size above which a given material will not planarize in a single-film application.

A calculation method has been described for the determination of long-range planarization quality over a diverse patter... Results with a single film of photoresist have provided the basis for pursuit of a two-film approach, making use of a block mask (PBM) and an overcoat layer for improved planarization. Difficulties with optimizing PBM design to achieve true global planarization are discussed, particularly with regard to complex patterns where simple line/space interpretations are difficult. Finally, an etchback process with the ability to remove $\mathrm{SiO}_{2}$ and photoresist at a 1:1 etch rate ratio has been described and used to complete the global planarization process sequence, demonstrating feasibility of the PBM/etchback approach for planarization over a diverse pattern.

\section{Acknowledgment}

The authors would like to extend their appreciation to Nancy Kenyon for her invaluable processing support.

Manuscript submitted March 23, 1990; revised manuscript received Aug. 27, 1990. This was Paper 208 presented at the Los Angeles, CA, Meeting of the Society, May $7-12,1989$.

IBM assisted in meeting the publication costs of this article.

REFERENCES

1. H. Hazuki and T. Moriya, VMIC Conf. Proc., 121 (1986).
2. L. Stillwagon, R. Larson, and G. Taylor, This Journal, 134, 2030 (1987).

3. H. Gokan, M. Mukainaru, and N. Endo, ibid., 135, 1019 (1988).

4. U. Gritsch, G. Higelin, G. Enders, and W. Muller, VMIC Conf. Proc., 69 (1988).

5. G. DeGraaf, A. L. Butler, and R. Penning DeVries, ibid., 357 (1988).

6. L. DeBruin and J. M. F. G. van Laarhoven, ibid:; 404 (1988).

7. A. Schiltz and M. Pons, This Journal, 133, 178 (1986).

8. P. Riley and E. Castel, IEEE Trans. Semicond. Manufact., 1, 154 (1988).

9. R. H. Wilson and P. A. Piacente, This Journal, 133, 981 (1986).

10. S. Fujii, M. Fukumoto, G. Fuse, and T. Ohzone, IEEE Trans. Electron Devices, ED-35, 1829 (1988).

11. D. J. Sheldon, C. W. Gruenschlaeger, L. Kammerdiner, N. B. Henis, P. Kelleher, and J. D. Haydan, IEEE Trans. Semicond. Manufact., 1, 140 (1988).

12. G. Fuse, H. Ogawa, K. Tateiwa, I. Nakao, S. Odanaka, M. Fukumoto, H. Iwasaki, and T. Ohzone, IEDM, 732 (1987).

13. T. H. Daubenspeck, C. W. Koburger, J. K. Debrosse, P. C. Sukanek, M. Armacost, P. C. Buschner, and J. A. Abernathey, Paper 208 presented at The Electrochemical Society Meeting, Los Angeles, CA, May 7-12, 1989 .

14. B. Davari, C. Koburger, R. Schultz, T. Furukawa, J. Warnock, M. Jost, M. Kerbaugh, and J. Mauer, Submitted to 1989 IEDM (Washington, DC).

15. R. H. Myers, "Response Surface Methodology," Edward Bros., Inc., Ann Arbor, MI (1976).

16. A. S. Bergendahl, S. F. Bergeron, and D. L. Harmon, IBM J. Res. Dev., 26, 580 (1982).

17. P. L. deBruin and J. M. F. G. van Laarhoven, Proceedings of the IEEE VLSI Multilevel Interconnection Conference, p. 404, IEDM, Washington, DC (1988).

\title{
Transport Phenomena in Tungsten LPCVD in a Single-Wafer Reactor
}

\author{
C. R. Kleijn and C. J. Hoogendoorn \\ Faculty of Applied Physics, Delft University of Technology, 2600 GA Delft, The Netherlands \\ A. Hasper, J. Holleman, and J. Middelhoek \\ Faculty of Electrical Engineering, University of Twente, 7500 AE Enschede, The Netherlands
}

\section{ABSTRACT}

The influence of the $\mathrm{WF}_{6}$ concentration on the growth rate in tungsten $\mathrm{LPCVD}$ from $\mathrm{WF}_{6}$ and $\mathrm{H}_{2}$ has been studied both experimentally in a coldwall single-wafer reactor and with the use of a mathematical simulation model, predicting the gas flow, heat transfer, species transport, and chemical reactions in the reactor. Model predictions were in very good agreement with experimental growth rates and uniformities. The growth rate was found to be independent of the $\mathrm{WF}_{6}$ inlet pressure above a certain value $P_{\text {crit }}$, whereas for $\mathrm{WF}_{6}$ inlet pressures below $P_{\text {crit }}$ the growth rate decreases linearly with the $\mathrm{WF}_{6}$ inlet pressure. It is shown that this transition is due to mass-transfer limitations rather than a change in the reaction mechanism. The value of $P_{\text {crit }}$ depends on the reactor geometry and process conditions and may be obtained experimentally or from model simulations as presented in this study. It is shown that large concentration gradients may be present in CVD reactors, even at low reactant conversion rates, and that criteria for "gradientless" reactor operation based on conversion rates are incorrect. We propose a better criterion, based on the value of $P_{\text {crit. }}$ It is also shown that thermal diffusion phenomena in coldwall reactors are very important. As a result, $\mathrm{WF}_{6}$ concentrations at the wafer surface will always be significantly lower than the inlet concentration.

In the last few years, the interest in the use of tungsten in multilevel metallization IC technology has grown considerably (1-5). Tungsten can be used as a diffusion barrier between silicon and aluminum, as a shunting material on gate structures, and for the filling of vias and contact holes (6-8). The latter application requires deposition techniques capable of filling submicron, high aspect ratio holes with excellent conformality (high step coverage). Blanket tungsten LPCVD from $\mathrm{H}_{2}-\mathrm{WF}_{6}$, according to the overall reaction

$$
\mathrm{WF}_{6}+3 \mathrm{H}_{2} \rightarrow \mathrm{W}+6 \mathrm{HF}
$$

with subsequent backetching, is now widely used for this purpose (9-12). Recently, W-LPCVD from $\mathrm{SiH}_{4}-\mathrm{WF}_{6}$ has been discovered as an attractive alternative, offering many advantages such as a high and temperature-independent growth rate, smaller grain size, and less interaction with silicon (12-18). The poor step coverage, however, seems to make this process unsuitable for via filling in a blanket mode $(19,20)$. Like many other LPCVD processes, W- 
LPCVD from $\mathrm{H}_{2}-\mathrm{WF}_{6}$ has been developed in hotwall multiple-wafer-in-tube LPCVD reactors (21-25), but the use of coldwall (single-wafer) reactors is now more common (26-30). Coldwall single-wafer reactors offer several advantages over conventional hotwall systems, such as low particle contamination, low $\mathrm{WF}_{6}$ consumption, suppression of gas phase reactions, efficient removal of reaction by-products, excellent uniformity on large wafers, and easier wafer handling.

The deposition rate of tungsten from $\mathrm{H}_{2}$ and $\mathrm{WF}_{6}$ in LPCVD appears to be fully determined by surface chemistry. For sufficiently high $\mathrm{WF}_{6}$ concentrations, the deposition rate has been found to depend on the $\mathrm{H}_{2}$ partial pressure and the temperature, being independent of the $\mathrm{WF}_{6}$ partial pressure, according to

$$
R_{\mathrm{kin}}=c_{0}\left[P_{\mathrm{WF}_{6}}\right]^{0}\left[P_{\mathrm{H}_{2}}\right]^{1 / 2} \exp \left(-E_{\mathrm{A}} / R T\right)
$$

with $E_{\mathrm{A}} \cong 67-73 \mathrm{~kJ} / \mathrm{mol}(8,21,23,26,31)$. However, at very low $\mathrm{WF}_{6}$ partial pressures the growth rate has been found to decrease with decreasing $\mathrm{WF}_{6}$ concentration. This has been ascribed to mass-transfer limitations (27) and to changes in the reaction mechanism (32). In either case variations in the $\mathrm{WF}_{6}$ concentration at the wafer surface will lead to nonuniform growth. Several other important qualities of tungsten films deposited through LPCVD from $\mathrm{H}_{2}-\mathrm{WF}_{6}$ seem to depend highly on the concentration, pressure, and temperature distributions in the reactor and at the wafer surface. Low temperatures, low $\mathrm{WF}_{6}$ concentrations, and low concentrations of reaction-products have been mentioned by several authors as factors favoring selective deposition $(21,24,30,33-35)$. Step coverage appears to be improved by high $\mathrm{WF}_{6}$ partial pressures, low temperatures, and low $\mathrm{H}_{2}$ partial pressures $(19,20,36,37)$. Encroachment (undesired $\mathrm{W}$ growth in contact windows just underneath $\mathrm{SiO}_{2}$ ) has been found to decrease with decreasing temperature and $\mathrm{WF}_{6}$ pressure (38).

From the above it may be clear that it is important to have precise knowledge of the concentration and temperature distributions in W-LPCVD reactors. These distributions are mainly determined by hydrodynamics and transport phenomena in the gas mixture in the reactor. Especially in single-wafer reactors, where deposition rates have to be high in order to obtain sufficient throughput and reactor walls are cooled (leading to a high rate of reactant consumption and reaction-product formation and to strong thermal diffusion effects) significant concentration and temperature gradients will be present. Transport phenomena in CVD reactors may be studied in detail with the aid of mathematical simulation models describing the gas flow, the heat transfer and species diffusion, and the chemical reactions in the gas mixture. Such models have been developed successfully for various types of atmospheric pressure CVD reactors and for hotwall multiple-wafer LPCVD reactors $(39,40)$. Relatively few models for LPCVD in coldwall single-wafer reactors have been published. In a previous study we have presented a model for polysilicon LPCVD in a single-wafer reactor (4). It was shown that such a model should incorporate phenomena which have often been neglected in CVD modeling. Other models for LPCVD in single-wafer reactors (42-44) have been based on commercially available general-purpose computational fluid dynamics codes, which do not incorporate several aspects which are relevant for accurate CVD modeling, such as multicomponent (thermal) diffusion and the influence of composition on the gas mixture properties.

It is the purpose of this paper to present a mathematical model for tungsten LPCVD from $\mathrm{H}_{2}-\mathrm{WF}_{6}$ in a coldwall single-wafer reactor and to validate the model predictions with experimental results. Several diagnostic tools may be used for the validation of CVD reactor simulation models. The most straightforward way is to compare predicted growth rates and growth uniformities with experimental observations. In tungsten LPCVD from $\mathrm{H}_{2}-\mathrm{WF}_{6}$, this method has limited value because of the insensitivity of the growth rate on the $\mathrm{WF}_{6}$ concentration (Eq. [2]). However, the observed dependence of the growth rate on the $\mathrm{WF}_{6}$ concentration at very low $\mathrm{WF}_{6}$ concentrations may be used to test a simulation model. A second possibility is the combination of a reactor simulation model with models for the prediction of microscopic film qualities and to compare predictions of these combined models with experimental results. Step coverage models, for example, predict a strong dependence of the step coverage on the $\mathrm{WF}_{6}$ concentration at the pore mouth $(19,20,36,37)$. Now, by using the $\mathrm{WF}_{6}$ concentration at the wafer surface as calculated from the reactor model as a boundary condition for the step coverage model and comparing predicted step coverages with experimental observations, the combination of reactor model and step coverage model may be tested $(20$, 44,45 ). A third possibility for the validation of a CVD reactor simulation model is the use of in situ laser diagnostic techniques for measuring temperatures and species concentrations in the gas mixture and to compare these values to model predictions (46). This is a topic of present research. In this study, we have simulated tungsten LPCVD from $\mathrm{H}_{2}$ and $\mathrm{WF}_{6}$ in a coldwall single-wafer reactor and we have compared predicted growth rates and uniformities at high and low $\mathrm{WF}_{6}$ concentrations to experimental results. Thus, we were able to test our simulation model. At the same time more insight was gained in the processes influencing the growth rate at low $\mathrm{WF}_{6}$ concentrations. This knowledge is important, because (i) for economic reasons it is interesting to use as little $\mathrm{WF}_{6}$ as possible, and (ii) for the accurate prediction of step coverage, precise knowledge of the mechanisms determining the growth rates at low $\mathrm{WF}_{6}$ concentrations is essential, since the $\mathrm{WF}_{6}$ concentration inside trenches or contact holes may be very low.

\section{Mathematical Model}

The mathematical model for the simulation of transport phenomena and chemical reactions in a coldwall singlewafer reactor has been discussed in detail elsewhere (41). Here we will only give a brief description of the model and the implementation of the $\mathrm{H}_{2}-\mathrm{WF}_{6}$ process into the model, and we will amplify on some refinements which have recently been included. The model assumes steady-state conditions, laminar gas flow, and ideal gases, as well as the validity of the continuum approach. Since tungsten LPCVD from $\mathrm{H}_{2}-\mathrm{WF}_{6}$ is believed to be a fully heterogeneous process, gas-phase reactions have not been taken into account.

Transport equations.-The gas flow and heat transfer in an $\mathrm{N}$ component gas mixture are described by the continuity equation [3], the momentum balance equation or Navier-Stokes equation [4], and the energy equation [5] (symbols are explained in the List of Symbols)

$$
\nabla \cdot(\rho \mathbf{v})=0
$$

$$
\nabla \cdot(\rho \mathbf{v v})=\nabla \cdot\left(\mu\left(\nabla \mathbf{v}+(\nabla \mathbf{v})^{\mathrm{T}}\right)-\frac{2}{3} \mu(\nabla \cdot \mathbf{v}) \cdot \underline{\underline{I}}\right)-\nabla P+\rho \mathbf{g}
$$

$$
c_{\mathrm{p}} \nabla \cdot(\rho \mathbf{v} T)=\nabla \cdot(\lambda \nabla T)+\nabla \cdot\left(R T \sum_{i=1}^{\mathrm{N}} \frac{\mathbb{D}_{\mathrm{i}}^{\mathrm{T}}}{m_{\mathrm{i}}} \nabla\left(\ln f_{1}\right)\right)
$$

The last term in Eq. [5] represents the Dufour effect (diffusion-thermo effect), which is the "reciprocal process" to the Soret effect (thermal diffusion effect). The first causes an energy flux as a result of concentration gradients in a gas mixture, whereas the second causes species diffusion fluxes as a result of temperature gradients. The Dufour effect was not included in our previous model (41). In this study we have found that its influence on calculated temperatures is negligible $(<0.1 \%)$ for the process conditions studied and we feel that this conclusion may be extrapolated to LPCVD processes in general.

The balance equation for gas species $\mathrm{i}$ can be written as

$$
\nabla \cdot\left(\rho \mathbf{v} \omega_{1}\right)=-\nabla \cdot\left(\mathbf{j}_{1}^{\mathrm{c}}+\mathbf{j}_{\mathrm{i}}^{\mathrm{T}}\right) \quad(\mathrm{i}=1, \mathrm{~N}-\mathbf{1})
$$

The ordinary (concentration) diffusion mass fluxes are obtained from the Stefan-Maxwell equations (in mass fractions and mass fluxes) 


$$
\nabla \omega_{\mathrm{i}}+\omega_{\mathrm{i}} \nabla(\ln M)=\frac{M}{\rho} \sum_{\mathrm{j} \neq \mathrm{i}} \frac{1}{m_{\mathrm{j}} D_{\mathrm{ij}}}\left(\omega_{\mathrm{j}} \mathrm{j}_{\mathrm{j}}^{\mathrm{c}}-\omega_{\mathrm{j}} \mathrm{j}_{\mathrm{i}}^{\mathrm{c}}\right) \quad(\mathrm{i}=1, \mathrm{~N}-\mathbf{1})
$$

Since the mass fractions of the $\mathrm{N}$ species must sum up to 1 and the diffusive mass fluxes must sum up to 0 , there are only N-1 independent equations of the forms of Eq. [6] and [7]. The thermal diffusion mass fluxes are calculated from

$$
\mathbf{j}_{\mathrm{i}}^{\mathrm{T}}=-\mathbb{D}_{\mathrm{i}}^{\mathrm{T}} \nabla(\ln T)(\mathbf{i}=1, \mathrm{~N})
$$

Transport properties.-The transport properties of the individual gas species and the binary ordinary diffusion coefficients are calculated from Chapman-Enskogg kinetic theory, assuming Lennard-Jones (6-12) interaction potentials (50). Lennard-Jones parameters for the gas species are given in Table I. Semiempirical mixture rules are used for calculating the transport properties of the gas mixture as a function of pressure, temperature, and mixture composition. Previously (41) we have used an approximate method for calculating multicomponent thermal diffusion coefficients. Because of the great importance of thermal diffusion phenomena in gas mixturés containing $\mathrm{H}_{2}$ and $\mathrm{WF}_{6}$, we have used the exact formulations (Ref. (50) pp. 538-543) in this study. For a typical gas mixture consisting of $80 \%$ $\mathrm{H}_{2}, 10 \% \mathrm{Ar}, 5 \% \mathrm{WF}_{6}$, and $5 \% \mathrm{HF}$ at a temperature of $600 \mathrm{~K}$ the $\mathrm{WF}_{6}$ multicomponent thermal diffusion coefficient obtained from the approximate formulation was found to be $45 \%$ lower compared to the exact formulation. The calculation of multicomponent thermal diffusion coefficients requires great computational effort and increases the overall CPU time needed by almost $40 \%$.

Boundary conditions.-Boundary conditions must be specified for the velocity vector, the temperature, and the species concentrations in the inflow and the outflow of the reactor, on solid, nonreacting walls and on the wafer surface

Inflow

$$
\begin{gathered}
\mathbf{n} \cdot \mathbf{v}=v_{\text {in }} \text { and } \mathbf{n} \times \mathbf{v}=0 \\
T=T_{\text {in }} \\
\omega_{\mathrm{i}}=\omega_{\mathrm{i}, \mathrm{In}} \text { and } \mathbf{n} \cdot\left(\mathbf{j}_{\mathrm{i}}^{\mathrm{c}}+\mathbf{j}_{\mathrm{i}}^{\mathrm{T}}\right)=0
\end{gathered}
$$

Outflow

$$
\begin{gathered}
\mathbf{n} \cdot(\nabla \rho \mathbf{v})=0 \text { and } \mathbf{n} \times \mathbf{v}=\mathbf{0} \\
\mathbf{n} \cdot \nabla T=0 \\
\mathbf{n} \cdot \nabla \omega_{\mathrm{i}}=0
\end{gathered}
$$

Solid walls

$$
\begin{aligned}
& \mathbf{v}=0 \\
& T=T_{\text {wall }} \text { or } \mathbf{n} \cdot \nabla T=0 \\
& \mathbf{n} \cdot\left(\mathbf{j}_{\mathbf{i}}^{\mathrm{c}}+j_{\mathrm{i}}^{\mathrm{T}}\right)=0
\end{aligned}
$$

Wafer surface

$$
\begin{gathered}
\mathbf{n} \cdot(\rho \mathbf{v})=R_{\text {eff }} \sum_{i=1}^{N} m_{i} \gamma_{i} \text { and } \mathbf{n} \times \mathbf{v}=0 \\
T=T_{\text {wafer }} \\
\mathbf{n} \cdot\left(\rho \omega_{\mathrm{i}} \mathbf{v}+\mathbf{j}_{\mathrm{i}}^{\mathrm{c}}+\mathbf{j}_{\mathrm{i}}^{\mathbf{T}}\right)=m_{\mathrm{i}} \gamma_{\mathrm{i}} R_{\text {eff }}
\end{gathered}
$$

with $\mathbf{n}$ a unity vector normal to the inflow/outflow opening

\begin{tabular}{|c|c|c|c|c|}
\hline Gas & $\begin{array}{c}m \\
\left(\mathrm{~kg} \cdot \mathrm{mol}^{-1}\right)\end{array}$ & $\left(\begin{array}{c}\sigma \\
(\AA)\end{array}\right)$ & $\stackrel{\epsilon / \mathrm{k}}{(\mathrm{K})}$ & Reference \\
\hline $\begin{array}{l}\mathrm{H}_{2} \\
\mathrm{WF}_{6} \\
\mathrm{HF} \\
\mathrm{Ar}\end{array}$ & $\begin{array}{l}0.002016 \\
0.29784 \\
0.02001 \\
0.039944\end{array}$ & $\begin{array}{l}2.827 \\
5.21 \\
3.138 \\
3.542\end{array}$ & $\begin{array}{l}59.7 \\
338 \\
330 \\
93.3\end{array}$ & $\begin{array}{c}(47) \\
(48,49)^{\mathrm{a}} \\
(47) \\
(47)\end{array}$ \\
\hline
\end{tabular}
or wall/wafer surface.

Surface reaction and mass-transfer-limited growth-For sufficiently high $\mathrm{WF}_{6}$ concentrations, the reaction rate of the surface reaction is given by Eq. [2]. At very low $\mathrm{WF}_{6}$ concentrations, however, the overall growth rate cannot remain independent of the $\mathrm{WF}_{6}$ pressure, because of masstransfer limitations. It is also possible that the reaction rate changes from zero order to nonzero order in $\mathrm{WF}_{6}$ at low $\mathrm{WF}_{6}$ concentrations. Van der Putte (32), for example, assumed the reaction to be $1 / 6$ order in $\mathrm{WF}_{6}$ at low $\mathrm{WF}_{6}$ concentrations. In this study, we have assumed that the rate of the heterogeneous reaction remains zero order in $W_{6}$
Table 1. Lennard-Jones Parameters

a Estimated from critical parameters, using $T_{\mathrm{c}}=443 \mathrm{~K}, T_{\mathrm{B}}=290.2$ $\mathrm{K}, V_{\mathrm{c}}=227.9 \mathrm{~cm}^{3} / \mathrm{mol}, V_{\mathrm{B}}=86.63 \mathrm{~cm}^{3} / \mathrm{mol}$, and $P_{\mathrm{e}}=42.7 \mathrm{bar}$.

down to very low pressures. This assumption is supported by our experimental growth rate measurements, as will be discussed later. The overall growth rate is described by a mechanism that considers the sequential processes of gasphase diffusion of reactants to the wafer surface and a zero order heterogeneous reaction, as was done by Ulacia et al. (42)

$$
\frac{1}{R_{\text {eff }}}=\frac{1}{R_{\mathrm{k} 1 \mathrm{n}}}+\frac{1}{R_{\mathrm{D}, \mathrm{WF}_{6}}}+\frac{3}{R_{\mathrm{D}, \mathrm{H}_{2}}}
$$

Here, $R_{\text {eff }}$ is the deposition rate, $R_{\text {kin }}$ is the reaction rate determined by the heterogeneous reaction kinetics, and $R_{D, i}$ is the maximum diffusion flux of species i to the wafer surface. Through Eq. [13], the slowest of the three mechanisms, diffusion of $\mathrm{WF}_{6}$ to the wafer, diffusion of $\mathrm{H}_{2}$ to the wafer, and heterogeneous reaction at the wafer surface, determines the deposition rate. Usually a large excess of $\mathrm{H}_{2}$ is used, so $R_{\mathrm{D}, \mathrm{H}_{2}} \gg R_{\mathrm{D}, \mathrm{WF}_{6}}$. Based on the extensive set of experimental growth rates published by Broadbent and Ramiller (23), $R_{\text {kin }}$ was calculated from Eq. [2], using

$$
\begin{gathered}
c_{0}=1.7 \mathrm{~mol} \cdot \mathrm{Pa}^{-1 / 2} \cdot \mathrm{m}^{-2} \cdot \mathrm{s}^{-1} \\
E_{\mathrm{A}}=69 \mathrm{~kJ} \cdot \mathrm{mol}^{-1} \cdot \mathrm{K}^{-1}
\end{gathered}
$$

with a statistical error of $\pm 0.5 \mathrm{~mol} \cdot \mathrm{Pa}^{-1 / 2} \cdot \mathrm{m}^{-2} \cdot \mathrm{s}^{-1}(95 \%)$ in the value of $c_{0}$ at fixed $E_{\mathrm{A}}$. The maximum mole flux of species i to the wafer surface $R_{\mathrm{D}, \mathrm{i}}$ is calculated from the maximum diffusive flux from the first discretization grid point to the wafer surface as

$$
R_{\mathrm{D}, \mathrm{i}}=\frac{1}{m_{\mathrm{i}}} \frac{\rho^{1} \mathbb{D}_{\mathrm{i}}^{1} \omega_{\mathrm{i}}^{1}}{\Delta}
$$

where the superscript 1 denotes the value in the first grid point next to the wafer surface, $\Delta$ is the distance from the wafer surface to this point (1 $\mathrm{mm}$ on the standard grid), and $\mathbb{D}_{i}$ is an effective ordinary diffusion coefficient for species $i$ in the gas mixture, calculated from

$$
\mathbb{D}_{\mathrm{i}}=-\frac{\mathbf{j}_{\mathrm{i}}^{\mathrm{c}}}{\rho \nabla \omega_{\mathrm{i}}}
$$

Note that Eq. [15] has been based on the fact that the species diffusion to the wafer surface reaches a maximum when the species concentration at the wafer surface becomes zero. Since $\mathbb{U}_{i}^{T} \rightarrow 0$ for $\omega_{i} \rightarrow 0$, Eq. [15] does not include a thermal diffusion flux term.

Numerical solution method.-The above set of partial differential equations with boundary conditions is solved in two-dimensional, axisymmetric form, using a controlvolume-based finite difference method $(41,51)$. The equations are discretized on a nonuniform, cylindrical grid and are solved iteratively, using a TDMA line-by-line method. For most calculations a $35 \times 35$ grid was used. Grid independence was checked on $50 \times 50$ and $70 \times 70$ grids for some representative situations. The calculated deposition rates and species concentrations at the wafer surface obtained on these fine grids differed less than $3 \%$ from those obtained on the standard grid. Three convergence criteria were used: (i) the error in the global mass balance for the total flow, $<10^{-2} \%$, (ii) the error in the global mass balance for each of the gas species, $<1 \%$, and (iii) the residuals of the equations (absolute values, summed over the grid, nor- 


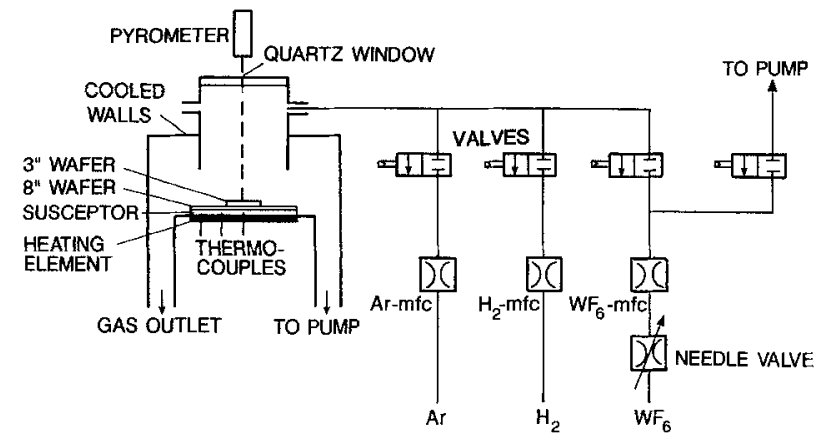

Fig. 1. Schematic representation of the reactor chamber with gas lines.

malized by a characteristic value for the variable and normalized by the number of grid points), $<10^{-6}$. Changes of less than $1 \%$ in the calculated deposition rates and wafer surface concentrations occurred when these criteria were reduced to $10^{-3}, 10^{-1}$, and $10^{-7 \%}$. All calculations were carried out on a HP 9000-835 minicomputer. To reach a converged solution on the standard grid, ca. 5000 iterations are needed taking $3.6 \mathrm{~s}$ per iteration.

\section{Experimental}

Tungsten LPCVD growth rates were studied experimentally in a loadlocked ASM coldwall single-wafer reactor which is designed for handling 8 in. wafers. In the present experiments, 3 in. p-type $10 \Omega \cdot \mathrm{cm}(100)$ wafers were used which were placed in the center of an 8 in. $\mathrm{SiO}_{2}$-coated carrier wafer. A schematic sketch of the reactor and gas lines is presented in Fig. 1. The walls of the cylindric stainless steel reactor chamber are water cooled. The wafer is placed facing upward on a $0.24 \mathrm{~m}$ diam graphite susceptor, which is placed on top of a quartz dome. The susceptor is heated indirectly by a resistance heating element, which is placed up against the inside upper wall of the quartz dome. The parts of the dome outside the susceptor are protected from heating up through radiation shields and remain relatively cold. Gases are introduced radially into a $0.20 \mathrm{~m}$ diam gas injection tube, which is positioned perpendicularly above the wafer surface. The purity of the gas sources $\left(\mathrm{WF}_{6}, \mathrm{Ar}, \mathrm{H}_{2}\right)$ employed in this study was $99.999 \%$ according to manufacturer's specifications. The upper wall of the reactor, opposite to the wafer surface, consists of a watercooled quartz window, allowing the silicon wafer surface temperature to be measured using a dual-wavelength py- rometer. In this way, the wafer temperature was known at the starting of the deposition with an accuracy of $\pm 5 \mathrm{~K}$. During the deposition, the susceptor temperature as measured by a series of thermocouples was kept constant. Since we wanted to run growth experiments at extremely low $W_{6}$ supplies, special attention was given to the calibration of the $\mathrm{WF}_{6}$ flow. Very low flows were realized by putting a needle vive in se ies with the mass flow controller (Fig. 1). Calibration was done by measuring the pressure rise in the known constant volume of the reactor with the outlet valves closed. Thus, we were able to adjust flows down to $0.4 \mathrm{sccm}$ with an accuracy of $\pm 0.05 \mathrm{sccm}$. Immediately before loading the wafer into the reactor, a HF (1:100) dip of 30s was applied. Deposition was stopped immediately at the moment that selectivity was lost at the susceptor and the carrier wafer, as could easily be observed visually by looking through the quartz window opposite to the susceptor. Layer thicknesses were measured by weight increase, with an accuracy of $\pm 0.05 \mathrm{mg}$, and by using a profilometer and were corrected for the thickness of the initial, silicon-reduced, tungsten layer. Using the first method, the overall thickness could be measured, from which the wafer average growth rate could be determined with an accuracy of $\pm 20 \AA / \mathrm{min}$. The profilometer measured the local thickness, thus allowing determination of growth rate uniformities. One has to realize, however, that profilometer measurements suffer from surface roughness. SEM observations showed that the effective roughness may be in the order of $10 \%$ of the total layer thickness for hydrogen-reduced LPCVD tungsten films.

\section{Results}

Modeling results.-In Fig. 2 examples of modeling results are shown. Figure 2a shows calculated streamlines for a total pressure $P_{\text {tot }}$ of $133 \mathrm{~Pa}$, a wafer temperature $T_{\text {wafer }}$ of $673 \mathrm{~K}$, and an inlet flow of $1200 \mathrm{sccm}$, consisting of 1000 sccm $\mathrm{H}_{2}, 100 \mathrm{sccm} \mathrm{WF}_{6}$, and $100 \mathrm{sccm}$ Ar. It can be seen that a stable gas flow, which is not disturbed by buoyancy effects, can be obtained at these low pressures in coldwall reactors with the heated susceptor facing upward. In Fig. $2 b$ calculated isotherms are shown. There is no thin thermal boundary layer and the temperature distribution in the gas mixture is determined by conduction, rather than convection. The growth rate is fully determined by surface reaction kinetics and is highly uniform, as shown in Fig. 3. Due to the $460 \AA / \mathrm{min}$ deposition on the $8 \mathrm{in}$. wafer, $3.6 \mathrm{sccm} \mathrm{WF}_{6}$ and $10.8 \mathrm{sccm} \mathrm{H}_{2}$ are consumed and $21.6 \mathrm{sccm} \mathrm{HF}$ is produced. In Fig. 2c and $\mathrm{d}$ the resulting $\mathrm{HF}$ and $\mathrm{WF}_{6}$ mole concentrations in the reactor are shown.
Fig. 2. Examples of model predictions. (a) Streamlines for $P_{\text {tot }}=$ $133 \mathrm{~Pa}, T_{\text {wofer }}=673 \mathrm{~K}$, and $\mathrm{Q}_{\mathrm{H}_{2}}=$ $1000, Q_{W F_{6}}=100$, and $Q_{A r}=100$ $\mathrm{sccm}$. Deposition on a 8 in. wafer surface. Streamline values are 0.1 $0.2, \ldots, 0.9$, normalized at the incoming mass flow. (b) Isotherms for the same process conditions. (c) HF mole fractions for the same process conditions. (d) $\mathrm{WF}_{6}$ mole fractions for the same process conditions. (e) $W F_{6}$ mole fractions for $Q_{\mathrm{WF}_{6}}=10$ and $Q_{\mathrm{Ar}}=190 \mathrm{sccm}$, other parameters as in (o-d). (f) $W F_{6}$ mole froctions for $Q_{W_{6}}=1$ and $Q_{A r}=199 \mathrm{sccm}$, other parameters as in (a-d).
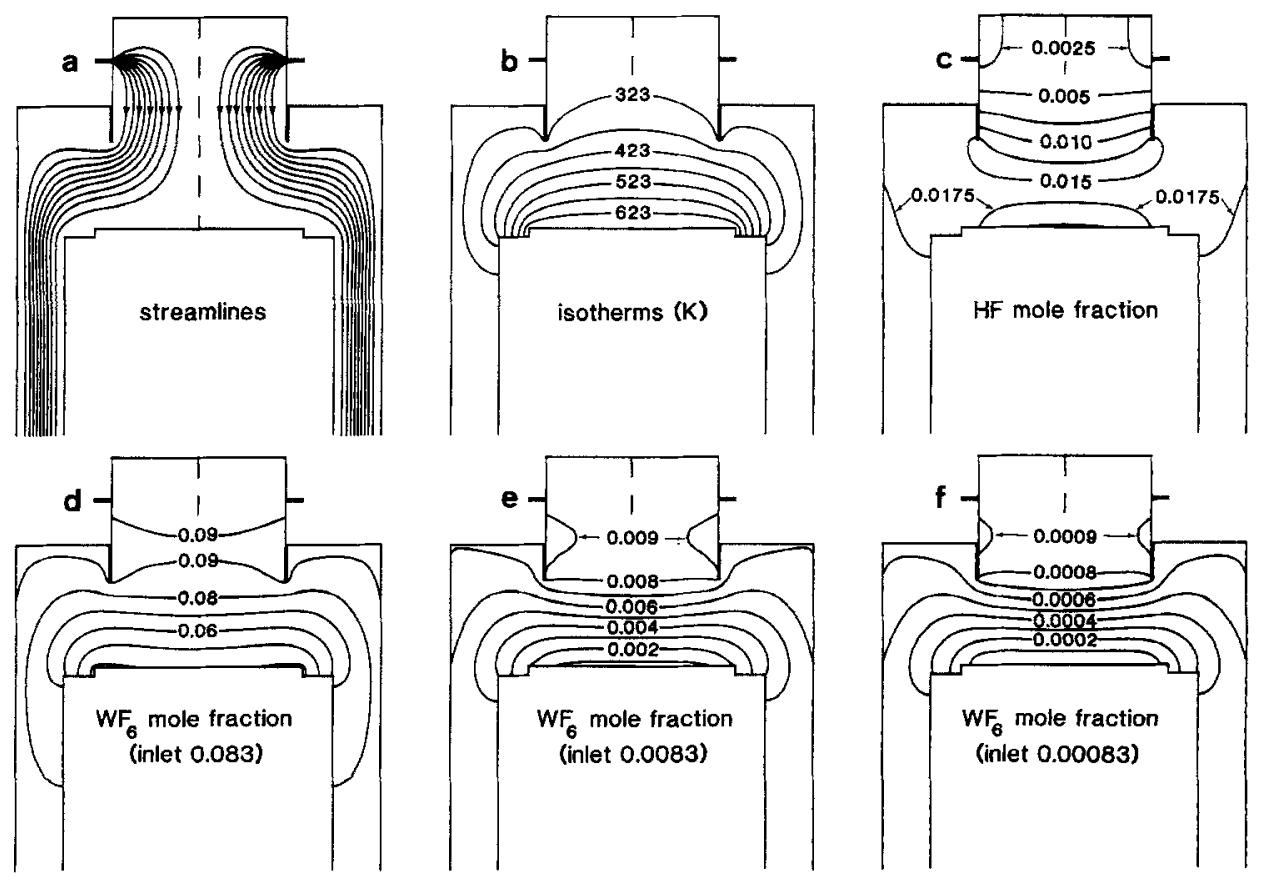


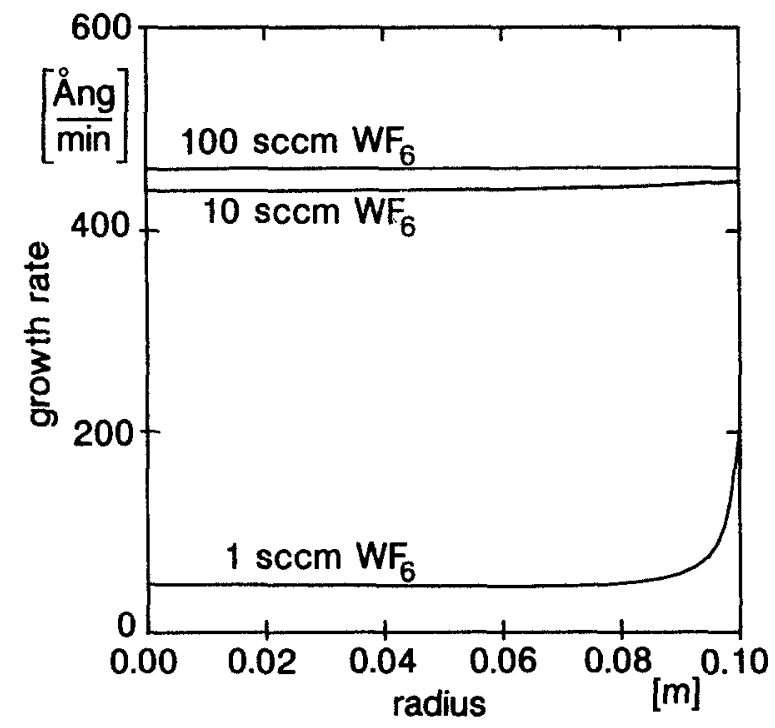

Fig. 3. Predicted growth rates as a function of radius for the cases corresponding to Fig. 2a-d, e and $f$.

Although only $3.6 \%$ of the incoming $\mathrm{WF}_{6}$ is consumed, the $\mathrm{WF}_{6}$ concentration at the wafer surface is less than $50 \%$ of the inlet concentration. This is due to the strong thermal diffusion effects, causing the heavy $\mathrm{WF}_{6}$ molecules to move away from the hot susceptor. In Fig. 2e the incoming $\mathrm{WF}_{6}$ flow is reduced to $10 \mathrm{sccm}$, whereas the Ar flow is increased to $190 \mathrm{sccm}$, keeping all other parameters as in Fig. $2 \mathrm{a}-\mathrm{d}$. In this case the growth rate is just beginning to be limited by $\mathrm{WF}_{6}$ transport and has slightly decreased to 440 $\AA /$ min (Fig. 3). Although the $\mathrm{WF}_{6}$ consumption is only $35 \%$, the $\mathrm{WF}_{6}$ concentration at the wafer surface is less than $10 \%$ of the inlet concentration. In Fig. $2 f$ the $\mathrm{WF}_{6}$ inlet flow is further reduced to $1 \mathrm{sccm}$. Now, the growth rate is limited by $\mathrm{WF}_{6}$ transport to only $48 \AA \mathrm{A} / \mathrm{min}$ and is highly nonuniform (Fig. 3). The $\mathrm{WF}_{6}$ concentration at the wafer surface is zero and the $\mathrm{WF}_{6}$ consumption in this case is $46 \%$. This sequence illustrates the influence of the $\mathrm{WF}_{6}$ inlet pressure on the transition from kinetically limited to transportlimited growth and on the overall growth rate.

Comparison of model predictions with experimental results.-In Fig. 4 experimental results for the growth rate (averaged over the $3 \mathrm{in}$. wafer surface) as a function of the $\mathrm{WF}_{6}$ inlet pressure are shown. In this series of experiments the wafer temperature was $673 \mathrm{~K}$, the total pressure was

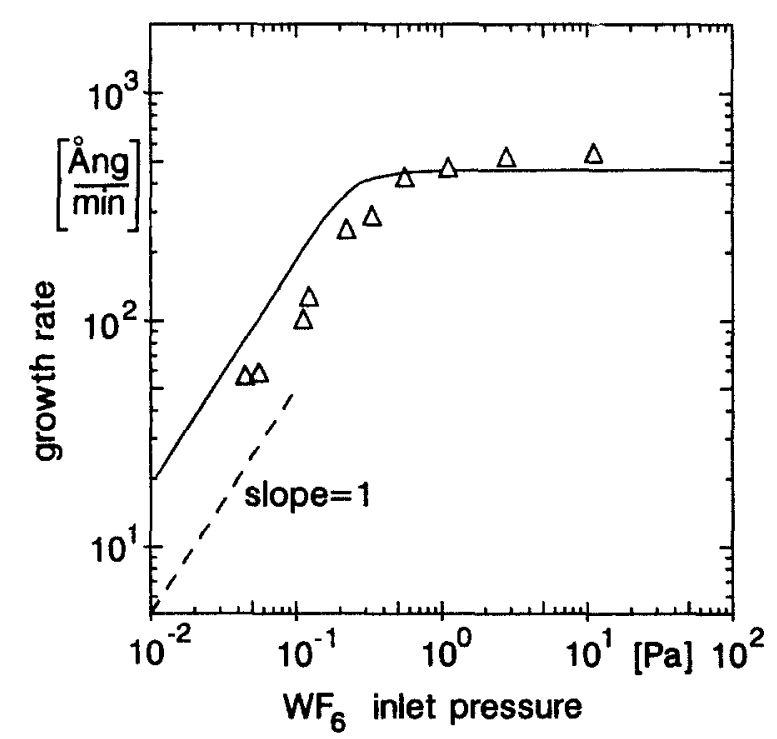

Fig. 4. Comparison of mole predictions ( - ) with experimental results $(\Delta)$ for the growth rate (averaged over the 3 in. wafer surface) as a function of the $W F_{6}$ inlet pressure $\left(P_{\text {tot }}=133 \mathrm{~Pa}, P_{\mathrm{in}, \mathrm{H}_{2}}=111 \mathrm{~Pa}, T_{\text {woter }}\right.$ $\left.=673 \mathrm{~K}, Q_{\text {tot }}=1200 \mathrm{sccm}\right)$.
$133 \mathrm{~Pa}$, the total flow was $1200 \mathrm{sccm}$, and the $\mathrm{H}_{2}$ flow 1000 $\mathrm{sccm}$. The $\mathrm{WF}_{6}$ flow was varied from 0.4 to $200 \mathrm{sccm}$, thus varying the $\mathrm{WF}_{6}$ inlet pressure by almost three orders of magnitude from 0.044 to $22 \mathrm{~Pa}$. Argon was used to keep the total flow fixed at $1200 \mathrm{sccm}$. The growth rate is independent of the $\mathrm{WF}_{6}$ inlet pressure above a certain critical value $P_{\text {crit, }}$, whereas for lower $\mathrm{WF}_{6}$ concentrations the growth rate decreases linearly with the $\mathrm{WF}_{6}$ inlet pressure. Also shown in Fig. 4 are results of model simulations for the same process parameters. The model fairly accurately predicts the $\mathrm{WF}_{6}$ independent growth rate for large $\mathrm{WF}_{6}$ concentrations, the linear dependence of the growth rate on the $\mathrm{WF}_{6}$ inlet pressure for low $W_{6}$ concentrations, and the transition point between these two regions. It should be noted that the model predictions in Fig. 4 were obtained without the introduction of any fitting parameter. It should also be noted that the model assumes a heterogeneous reaction rate which is zero order in $W_{6}$ for all $W_{6} F_{6}$ concentrations and that the decreasing growth rates for low $\mathrm{WF}_{6}$ concentrations predicted by the model are caused by masstransfer limitations only. Because of the good agreement between model predictions and experimental observations, we conclude that decreasing growth rates at low $\mathrm{WF}_{6}$ inlet concentrations are caused by mass-transfer limitations rather than a change in the reaction kinetics. More arguments supporting this conclusion will be discussed below.

When comparing model predictions and experimental results in detail, it can be seen that the model systematically overpredicts the growth rate in the region of low $\mathrm{WF}_{6}$ concentrations. This may possibly be explained by relatively small errors in the transport properties, especially in the (thermal) diffusion coefficients that were used in the model and that were obtained from theoretical predictions based on Chapman-Enskogg kinetic theory and LennardJones interaction potentials. For example, when the binary ordinary diffusion coefficient for $\mathrm{H}_{2}$ and $\mathrm{WF}_{6}$ was reduced by $40 \%$ compared to the theoretical value, keeping all other parameters fixed, a very good match between model predictions and experimental results could be obtained for all process conditions studied. An error of $40 \%$ in the predicted diffusion coefficient for a gaspair-like $\mathrm{H}_{2}$ and $\mathrm{WF}_{6}$ at high temperatures is not very unlikely, especially since Lennard-Jones force parameters for $\mathrm{WF}_{6}$ had to be estimated from critical parameters (Table I). For the binary ordinary diffusion coefficient of hydrogen and trimethylgallium, e.g., a difference of $70 \%$ was found between theoretical predictions and experimental results (52, 53). Therefore, we have used a binary ordinary diffusion coefficient for $\mathrm{H}_{2}$ and $\mathrm{WF}_{6}$ of 0.6 times the theoretical value in all further model simulations. Experimental determination of the binary diffusion coefficient for $\mathrm{H}_{2}-\mathrm{WF}_{6}$ at different temperatures is needed to further elucidate this assumption.

In Fig. 5, the experimental results from Fig. 4 are shown again, together with simulation results, using the adapted $\mathrm{H}_{2}-\mathrm{WF}_{6}$ diffusion coefficient. Also shown are comparisons between experimental and simulated growth rates for a series of experiments at different wafer temperatures and total pressures. In these series, a deviation between experimental and modeling results very similar to those in Fig. 4 was found when the uncorrected diffusion coefficient for $\mathrm{H}_{2} \mathrm{WF}_{6}$ was used. With the adapted diffusion coefficient, however, the model accurately predicts the growth rate as a function of the $\mathrm{WF}_{6}$ inlet pressure for all cases considered. Both the experiments and the model simulations show that the growth rate at low $\mathrm{WF}_{6}$ concentrations is linearly proportional to the $\mathrm{WF}_{6}$ inlet pressure, inversely proportional to the total pressure, and independent of the wafer temperature (at fixed total flow and reactor geometry). This again is an indication of the fact that decreasing growth rates at low $\mathrm{WF}_{6}$ inlet concentrations are caused by mass-transfer limitations rather than kinetical effects. Diffusion coefficients vary relatively little with temperature, causing the mass-transfer-limited growth rate to be almost independent of temperature. On the other hand, diffusion coefficients are inversely proportional to the total pressure, causing the mentioned effect of total pressure on the transfer limited growth rate at fixed $\mathrm{WF}_{6}$ pressure. 


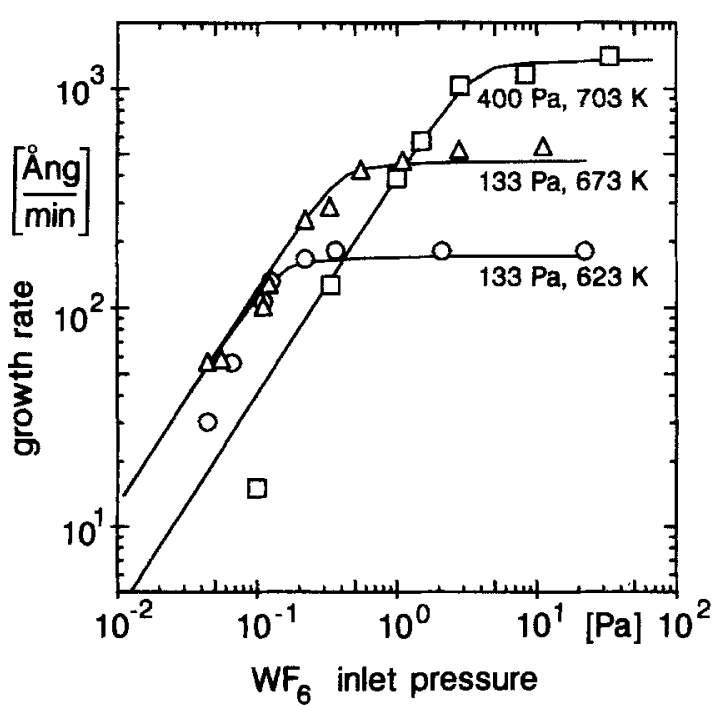

Fig. 5. Comparison of model predictions $(\longrightarrow$ ) with experimental results $(\triangle, \square, O)$, for the growth rate (averaged over the 3 in. wafer surface) as a function of the $W_{6}$ inlet pressure at different wafer temperatures and total pressures. In all cases, $Q_{\text {tot }}=1200$ and $Q_{\mathrm{H}_{2}}=$ $1000 \mathrm{sccm}$. In the model predictions the adapted ordinary diffusion coefficient for $\mathrm{WF}_{6}$ in $\mathrm{H}_{2}$ has been used.

When (at fixed wafer temperature, total pressure, and inlet species partial pressures) the total flow is increased, the convective transport of $\mathrm{WF}_{6}$ to the wafer surface will be increased, so $\mathrm{WF}_{6}$ will be less depleted and the $\mathrm{WF}_{6}$ concentration at the wafer surface will increase. Thus it is expected that the mass-transfer-limited growth rate will increase with increasing total flow. This is confirmed by two experiments at equal total pressure, $\mathrm{WF}_{6}$ inlet partial pressure, and wafer temperature, but differing total flows of 1200 and $4800 \mathrm{sccm}$, respectively, are presented in Table II. For the process conditions used, the surface kinetics determined growth rate would be ca. $460 \AA / \mathrm{min}$, assuming that Eq. [2] still holds at these low $\mathrm{WF}_{6}$ pressures. The same results are shown in Fig. 6 together with model simulations for total flows of 300-9600 sccm. Indeed, by increasing the total flow, the mass-transfer-limited growth rate is increased. Note however, that the effect of a large increase in total flow is relatively small, indicating that transport of $\mathrm{WF}_{6}$ from reactor inlet to wafer surface is mainly due to diffusion rather than convection. Also note, that a low $\mathrm{WF}_{6}$ consumption does not guarantee the exclusion of masstransfer limitations. Even at a total fow of $10 \mathrm{slm}$ and a $\mathrm{WF}_{6}$ consumption of only $3 \%$, the growth rate is highly reduced by mass-transfer limitations.

In Fig. 7 experimental and modeling results for the growth rate as a function of radius on a 3 in. wafer are shown for a total pressure of $133 \mathrm{~Pa}$, a wafer temperature of $673 \mathrm{~K}$, a hydrogen flow of $1000 \mathrm{sccm}$, a WF 6 flow of 1.3 $\mathrm{sccm}$, and an Ar flow of $198.7 \mathrm{sccm}$. The kinetically determined growth rate according to Eq. [2] is again ca. 460 $\AA /$ min. Both model predictions and experiments show a highly reduced, strongly nonuniform, mass-transferlimited deposition. Large variations in experimental growth rates obtained at different locations at fixed radii were found, especially at the edge of the wafer where the model predicts a strong variation of the growth rate with radius. These variations may possibly be ascribed to small asymmetries in the reactor configuration. Within this ex-

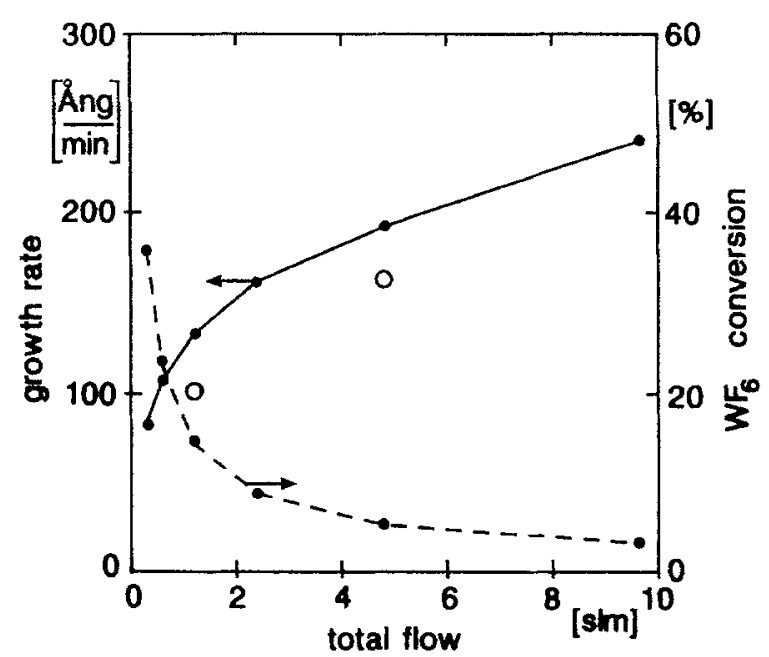

Fig. 6. Comparison of model predictions ( - ) with experimental results (0) for the growth rate (averaged over the $3 \mathrm{in}$. wafer surface) as a function of the total flow at fixed $W F_{6}$ inlet pressure. The dashed curve shows the calculated $W_{6}$ conversion. The kinetically determined growth rate is ca. $460 \AA / \mathrm{min}$. $\left(P_{\text {tot }}=133, P_{\mathrm{in}, \mathrm{H}_{2}}=111\right.$, and $P_{\mathrm{in},} \mathrm{wF}_{6}=$ $0.111 \mathrm{~Pa}, T_{\text {woter }}=673 \mathrm{~K}$.)

perimental error there is again a good agreement between model predictions and experimental results.

A criterion for "gradientless" operation.--In the above it has been shown that mass transfer and depletion phenomena may lead to strong concentration gradients in singlewafer LPCVD reactors, causing a large difference between the species inlet concentrations and the concentrations at the wafer surface. For fundamental CVD studies it is often desired to have precise knowledge of the species concentrations at the wafer surface. For this purpose, the concept of the "gradientless" CVD reactor, which is almost completely free of gradients in species concentrations, has been introduced (54). A gradientless CVD reactor is believed to be approximated under so-called "differential" operating conditions, i.e., at a low $(<10 \%)$ reactant conversion. As we have shown, this assumption is not correct, especially in the presence of strong thermal gradients. Even at very low reactant conversions, concentration gradients may be significant. Therefore, we propose a better criterion for "gradientless" operation. In the above we have shown that, for otherwise fixed process parameters, the growth rate is independent of the $\mathrm{WF}_{6}$ inlet partial pressure above a certain value $P_{\text {crit }}$ and decreases linearly with the $\mathrm{WF}_{6}$ inlet pressure below $P_{\text {crit }}$. The precise value of $P_{\text {crit }}$ depends on the reactor geometry and process conditions and should be determined experimentally. A rough estimate of $P_{\text {crit }}$ may be obtained from the fact that masstransfer limitations will be negligible when the surface reaction Damköhler number $R_{\text {kin }} L / \mathbb{D C}$, which is the ratio of the chemical reaction rate at the surface and the diffusive species transport, is small (55). We thus find for $P_{\text {crit }}$

$$
\frac{P_{\text {crit }}}{R T} \cong \frac{R_{\text {kin }} \mathrm{L}}{\mathbb{D}_{\mathrm{WF}_{6}}}
$$

where $L$ is a characteristic length for diffusion, which may roughly be taken as the distance from the wafer surface to the end of the inflow pipe, and the diffusion coefficient $\mathbb{D}_{\mathrm{WF}_{6}}$ for $\mathrm{WF}_{6}$ in excess hydrogen may be calculated from

Table II. Influence of the total flow on the growth rate

\begin{tabular}{|c|c|c|c|c|c|c|c|c|c|}
\hline \multicolumn{4}{|c|}{$\begin{array}{c}\text { Flow } \\
(\mathrm{sccm})\end{array}$} & \multicolumn{4}{|c|}{$\begin{array}{c}\text { Inlet pressure } \\
(\mathrm{Pa})\end{array}$} & \multirow{2}{*}{$\begin{array}{c}\text { Wafer } \\
\text { temperature } \\
(\mathrm{K})\end{array}$} & \multirow{2}{*}{$\begin{array}{l}\text { Growth } \\
\text { rate } \\
(\AA / \text { min })\end{array}$} \\
\hline $\mathrm{WF}_{6}$ & $\mathrm{Ar}$ & $\mathrm{H}_{2}$ & Total & $\mathrm{WF}_{6}$ & $\mathrm{Ar}$ & $\mathrm{H}_{2}$ & Total & & \\
\hline 1 & 199 & 1000 & 1200 & 0.11 & 22 & 111 & 133 & 673 & 101 \\
\hline 4 & 796 & 4000 & 4800 & 0.11 & 22 & 111 & 133 & 673 & 163 \\
\hline
\end{tabular}




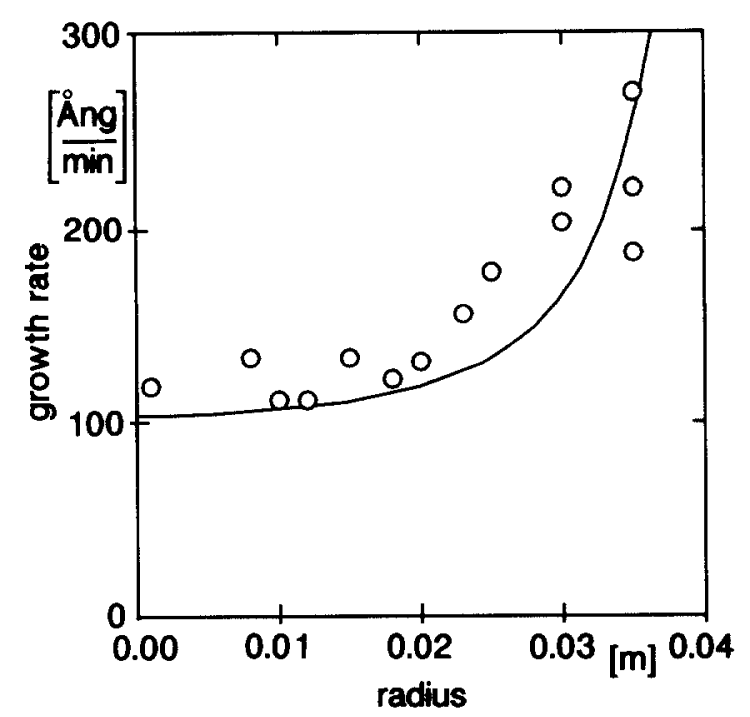

Fig. 7. Comparison of model predictions (-) with experimental results $(0)$ for the growth rate as a function of the radius on the 3 in. wafer surface. $\left(P_{\text {tot }}=133 \mathrm{~Pa}, T_{\text {wafer }}=673 \mathrm{~K}\right.$, and $Q_{\mathrm{H}_{2}}=1000, Q_{\mathrm{WF}_{6}}=$ 1.3 , and $\left.Q_{\mathrm{Ar}}=198.7 \mathrm{sccm}\right)$.

$$
\mathbb{D D W F}_{6}=1.4 \cdot 10^{-4} \frac{T^{1.7}}{P_{\text {tot }}}
$$

For the situations considered in this study, Eq. [17] was found to be accurate within a factor of five. Now, for $W_{6}$ inlet pressures $>>P_{\text {crit }}\left(\right.$ e.g., $\left.>10 \cdot P_{\text {crit }}\right)$, the $W_{6}$ concentration at the wafer surface will be close to the $\mathrm{WF}_{6}$ inlet concentration. However, notice that even under these conditions, the $\mathrm{WF}_{6}$ concentration at the wafer surface will be $25-50 \%$ lower than the inlet concentration in coldwall reactors due to thermal diffusion phenomena. We did extensive model variations, varying the kinetically determined deposition rate $R_{\text {kin }}(\therefore 100-5000 \AA / \mathrm{min})$, total pressure $P_{\text {tot }}$ (13.3-1330 Pa), deposition area $A$ (2-8 in. wafers) and total flow $Q_{\text {tot }}(0.3-10 \mathrm{slm})$, to study the influence of these parameters on the critical $W_{6}$ inlet pressure $P_{\text {crit }}$ in excess hydrogen. From these simulations the following relation, which may be used to extrapolate experimentally determined values of $P_{\text {crit }}$ to different operating conditions, was found

$$
\begin{aligned}
P_{\text {crit }} \propto & P_{\text {tot }} \cdot R_{\text {kin }} \cdot L \cdot A^{\alpha} \cdot Q_{\text {tot }}^{-\beta} \\
& \propto P_{\text {tot }} \cdot P_{\mathrm{H}_{2}^{*}}^{* 1 / 2} \cdot \exp \left(-E_{\mathrm{A}} / R T_{\text {wafer }}\right) \cdot L \cdot A^{\alpha} \cdot Q_{\text {tot }}^{-\beta}
\end{aligned}
$$

For $\alpha$ and $\beta$, values of 0.4 and 0.3 , respectively, were found. These values will probably be reactor-dependent and should be considered as indicative for vertical reactors of the impinging jet type, as the one described in this study, only. From Eq. [19] it is clear that increasing the total flow is a rather ineffective way for reducing transport limitations because of the small value of $\beta$. Although the above discussion was held for W LPCVD from $\mathrm{H}_{2}$ and $\mathrm{WF}_{6}$, it can more generally be applied to heterogeneous CVD processes which are zero order in the reactant concentration.

\section{Summary and Conclusions}

We have studied the influence of transport phenomena on growth rates in tungsten LPCVD from $W_{6}$ and $\mathrm{H}_{2}$, especially at low $\mathrm{WF}_{6}$ inlet concentrations. For this purpose a mathematical model, predicting the gas flow, heattransfer, species transport, and chemical reactions in the reactor has been developed. In the model the heterogeneous reaction rate is assumed to be zero-order in $W_{F}$ for all $\mathrm{WF}_{6}$ concentrations. Predicted growth rates have been compared to experimental values obtained in a coldwall, single-wafer LPCVD reactor. Both model predictions and experiments show that the growth rate is independent of the $\mathrm{WF}_{6}$ inlet concentration for large $\mathrm{WF}_{6}$ concentrations and linearly dependent on the $\mathrm{WF}_{6}$ inlet concentration for low $\mathrm{WF}_{6}$ concentratons. Without the introduction of any fitting parameters, there is a fairly good agreement between model predictions and experiments for a large range of process parameters. Through a slight adjustment of the theoretically predicted ordinary diffusion coefficient for $\mathrm{WF}_{6}$ in $\mathrm{H}_{2}$, a very good agreement could be obtained. We therefore conclude that the heterogeneous reaction rate is indeed zero-order in $\mathrm{WF}_{6}$ down to very low $\mathrm{WF}_{6}$ concentrations (at least down to partial pressures of ca. 0.2 $\mathrm{Pa}$ and that decreasing growth rates at low $\mathrm{WF}_{6}$ concentrations are caused by mass-transfer limitations rather than a change in the reaction mechanism. Other arguments supporting this conclusions are: (i) the observed first-order dependence of the growth rate on the $\mathrm{WF}_{6}$ inlet pressure at low $\mathrm{WF}_{6}$ concentrations, (ii) the observed temperature-independent growth rate at low $\mathrm{WF}_{6}$ inlet concentrations, (iii) the observed inverse proportionality of the growth rate on the total pressure at low $\mathrm{WF}_{6}$ inlet concentrations, $(i v)$ the highly nonuniform growth rates obtained at low $\mathrm{WF}_{6}$ inlet concentrations, and $(v)$ the influence of the total flow on the growth rate at fixed low $\mathrm{WF}_{6}$ inlet concentration. We also conclude that our model gives an accurate description of the most relevant chemical and physical phenomena in a single-wafer tungsten LPCVD reactor.

Our model simulations show that large species concentration gradients may be present in single-wafer LPCVD reactors even at very low conversion rates. Therefore, the conversion rate is not a good criterion for gradientless reactor operation. We have proposed a better criterion based on the minimal $\mathrm{WF}_{6}$ inlet pressure $P_{\text {crit }}$ required for kinetically limited growth, and we have presented an expression which allows the extrapolation of experimentally determined values for $P_{\text {crit }}$ to different process conditions. Our model simulations also indicate the great importance of thermal diffusion phenomena. Due to thermal diffusion, "gradientless" conditions can never be fully reached in coldwall reactors and $\mathrm{WF}_{6}$ wafer concentrations will always be $25-50 \%$ lower than the $\mathrm{WF}_{6}$ inlet concentration.

Finally, this study has shown that a sophisticated mathematical model for the transport phenomena and chemical reactions in CVD reactors may be very useful in interpreting results from growth experiments and in evaluating the influence of transport phenomena on kinetic data. The simulation model may furthermore be used for the calculation of the concentrations of reactants and reaction products at the wafer surface, which is necessary for the prediction of process qualities such as step coverage and selectivity.

\section{Acknowledgments}

This work forms part of the "Innovatief Onderzoeks Programma IC Technologie" (Innovative Research Program for IC Technology) and was made possible by the financial support from the Netherlands Ministry of Economic Affairs. Part of this research forms part of the research program of the "Stichting Fundamenteel Onderzoek der Materie" (Foundation for Fundamental Research of Matter-FDM) and was made possible by the financial support from the "Nederlandse Organisatie voor Zuiver Wetenschappelijk Onderzoek" (The Netherlands Organization for the Advancement of Pure Research-ZWO). ASMAMTC is acknowledged for support in the experimental part of this study.

Manuscript submitted May 14, 1990; revised manuscript received Sept. 7, 1990 .

Delft University of technology assisted in meeting the publication costs of this article.

\section{LIST OF SYMBOLS}

A deposition area, $\mathrm{m}^{2}$

$c_{0} \quad$ constant in reaction rate expression (Eq. [2]), $\mathrm{mol}$. $\mathrm{Pa}^{-1 / 2} \cdot \mathrm{m}^{-2} \cdot \mathrm{s}^{-1}$

$c_{\mathrm{p}} \quad$ specific heat of the gas mixture, $\mathrm{J} \cdot \mathrm{kg}^{-1} \cdot \mathrm{K}^{-1}$

$\mathrm{C}$ mole concentration of gaseous species $(=P / R T)$, $\mathrm{mol} \cdot \mathrm{m}^{-3}$

D binary ordinary diffusion coefficient, $\mathrm{m}^{2} \cdot \mathrm{s}^{-1}$

D effective ordinary diffusion coefficient, $\mathrm{m}^{2} \cdot \mathrm{s}^{-1}$

$\mathbb{D}^{\mathrm{T}} \quad$ multicomponent thermal diffusion coefficient, $\mathrm{multicompon}$ 
$E_{\mathrm{A}} \quad$ activation energy, $\mathrm{kJ} \cdot \mathrm{mol}^{-1} \cdot \mathrm{K}^{-1}$

$f$ species mole fraction

g gravity vector, $\mathrm{m}^{2} \cdot \mathrm{s}^{-1}$

G growth rate, $\AA \cdot \mathrm{min}^{-1}$

I unity tensor

j diffusive mass flux vector, $\mathrm{kg} \cdot \mathrm{m}^{-2} \cdot \mathrm{s}^{-1}$

$L \quad$ characteristic length for species diffusion, $m$

$m \quad$ mole mass, $\mathrm{kg} \cdot \mathrm{mol}^{-1}$

$M \quad$ averaged mole mass, $\mathrm{kg} \cdot \mathrm{mol}^{-1}$

$N$ number of gas species in the mixture

n normal unity vector

$P$ pressure, $\mathrm{Pa}$

$Q \quad$ flow rate, sccm

$R \quad$ universal gas constant, $\mathrm{J} \cdot \mathrm{mol}^{-1} \cdot \mathrm{K}^{-1}$

$R_{\text {eff }} \quad$ deposition rate, $\mathrm{mol} \cdot \mathrm{m}^{-2} \cdot \mathrm{s}^{-1}$

$R_{\text {kin }} \quad$ kinetically determined heterogeneous reaction rate, $\mathrm{mol} \cdot \mathrm{m}^{-2} \cdot \mathrm{s}^{-1}$

$R_{\mathrm{D}}$ maximum diffusive mole flux to the wafer surface, $\mathrm{mol} \cdot \mathrm{m}^{-2} \cdot \mathrm{s}^{-1}$

$T$ temperature, $\mathrm{K}$

v velocity vector, $m \cdot \mathrm{s}^{-1}$

$\mathbf{v}_{\text {in }} \quad$ inlet gas velocity, $\mathrm{m} \cdot \mathrm{s}^{-1}$

\section{Greek symbols}

$\gamma \quad$ stoichiometric coefficient for surface reaction

$\epsilon / \mathrm{k} \quad$ parameter in Lennard-Jones intermolecular poten-

tial function, $\mathrm{K}$

$\Delta \quad$ distance from wafer surface to first grid point, $m$

$\lambda$ thermal conductivity of the gas mixture, $\mathrm{W} \cdot \mathrm{m}^{-1}$. $\mathrm{K}^{-1}$

$\mu \quad$ dynamic viscosity of the gas mixture, $\mathrm{kg} \cdot \mathrm{m}^{-1} \cdot \mathrm{s}^{-1}$ $\mathrm{p}$ density of the gas mixture, $\mathrm{kg} \cdot \mathrm{m}^{-3}$

$\sigma \quad$ parameter in Lennard-Jones intermolecular potential function, $\AA$

$\omega$ species mass fraction

\section{Subscripts}

$i, j \quad$ with respect to gas species $i, j$

ij with respect to gas pair $i-j$

in in the inflow of the reactor

tot total.

wafer at the wafer surface

wall at the reactor wall

\section{Superscripts}

1 in the first grid point next to the wafer surface

c due to ordinary diffusion

$\mathrm{T}$ due to thermal diffusion

$T$ transposed vector

\section{REFERENCES}

1. "Tungsten and Other Refractory Metals for VLSI Applications," B. Blewer, Editor, The Materials Research Society, Pittsburgh, PA (1986).

2. "Tungsten and Other Refractory Metals for VLSI Applications II," E. Broadbent, Editor, The Materials Research Society, Pittsburgh, PA (1987).

3. "Tungsten and Other Refractory Metals for VLSI Applications III," V. Wells, Editor, The Materials Research Society, Pittsburgh, PA (1988).

4. "Tungsten and Other Refractory Metals for VLSI Applications IV," B. Blewer and C. McConica, Editors, The Materials Research Society, Pittsburgh, PA (1989).

5. "Tungsten and Other Advanced Metals for VLSI/ULSI Applications V," S. S. Wong and S. Furukawa, Editors, The Materials Research Society, Pittsburgh, PA (1990).

6. N. E. IMiller and I. Beinglass, Solid State Technol., 25, 85 (1982).

7. R. S. Blewer, ibid., 29, 117 (1986).

8. E. K. Broadbent and W. T. Stacy, ibid., 28, 51 (1985).

9. J. E. J. Schmitz, A. J. M. van Dijk, J. L. G. Suijker, M. J. Buiting, and R. C. Ellwanger, in "Proceedings of the European Workshop on Refractory Metals and Silicides," R. de Keersmaecker and K. Maex, Editors, p. 350, North-Holland Publishing Co., Amsterdam (1989).

10. J. E. J. Schmitz, R. C. Ellwanger, and A. J. M. van Dijk, in "Tungsten and Other Refractory Metals for VLSI Applications III," V. Wells, Editor, p. 55, The Materials Research Society, Pittsburgh, PA (1988).

11. R. V. Joshi, E. Mehter, M. Chow, M. Ishaq, S. Kang, P. Geraghty and J. McInerney, in "Tungsten and Other
Advanced Metals for VLSI/ULSI Applications V," S. S. Wong and S. Furukawa, Editors, p. 157, The Materials Research Society. Pittsburgh, PA (1990).

12. J. E. J. Schmitz, A. J. M. van Dijk, and M. W. M. Graef, in "Chemical Vapor Deposition," G. W. Cullen, Editor, PV 87-8, p. 625, The Electrochemical Society Softbound Proceedings Series, Pennington, NJ (1987).

13. R. S. Rosler, J. Mendoca, and M. J. Rice, J. Vac. Sci. Technol. B, 6(6), 1721 (1988).

14. T. Ohba, T. Suzuki, T. Hara, Y. Furumura, and K. Wada, in "Tungsten and Other Advanced Metals for VLSI/ULSI Applications V," S. S. Wong and S. Furukawa, Editors, p. 273, The Materials Research Society, Pittsburgh, PA (1990).

15. T. Ohba, T. Suzuki, T. Hara, Y. Furumura, and K. Wada, in "Tungsten and Other Refractory Metals for VLSI Applications IV," B, Blewer and C. M. McConica, Editors, p. 17, The Materials Research Society, Pittsburgh, PA (1989).

16. T. B. Gorczyca, L. R. Douglas, B. Gorowitz, and R. H. Wilson, This Journal, 136, 2765 (1989).

17. J. E. J. Schmitz, M. J. Buiting, and R. C. Ellwanger, in "Tungsten and Other Refractory Metals for VLSI Applications IV," B. Blewer and C. M. McConica, Editors, p. 27, The Materials Research Society, Pittsburgh, PA (1989).

18. H. L. Park, S. S. Yoon, C. O. Park, and J. S. Chun, Thin Solid Films, 181, 85 (1989).

19. J. E. J. Schmitz, W. L. N. van der Sluys, and A. H. Montree, in "Tungsten and Other Advanced Metals for VLSI/ULSI Applications V," S. S. Wong and S. Furukawa, Editors, p. 117, The Materials Research Society, Pittsburgh, PA (1990).

20. A. Hasper, C. R. Kleijn, J. Holleman, and J. Middelhoek, ibid., S. S. Wong and S. Furukawa, Editors p. 127, The Materials Research Society, Pittsburgh, PA (1990).

21. Y. Pauleau and Ph. Lami, This Journal, 132, 2779 (1985).

22. Ph. Iami and Y. Pauleau, ibid., 135, 980 (1988).

23. E. K. Broadbent and C. L. Ramiller, ibid., 131, 1427 (1984).

24. .. F. Tz Kwakman, W. J. C. Vermeulen, E. H. A. Granneman, and M. L. Hitchman, in "Tungsten and Other Refractory Metals for VLSI Applications III," V. Wells, Editor, p. 141, The Materials Research Society, Pittsburgh, PA (1988).

25. N. E. Miller and I. Beinglass, Solid State Technol., 23, $79(1980)$

26. C. M. MeConica and K. Krishnamani, This Journal, 133, 2542 (1986).

27. R. Blumenthal and G. C. Smith, in "Tungsten and Other Refractory Metals for VLSI Applications III," V. Wells, Editor, p. 47, The Materials Research Society, Pittsburgh, PA (1988)

28. A.E.T. Kuiper, M. F. C. Willemsen, and J. E. J. Schmitz, in "Proceedings of the European Workshop on Refractory Metals and Silicides," R. de Keersmaecker and K. Maex, Editors, p. 338, NorthHolland Publishing Co., Amsterdam (1989).

29. T. S. Cale, M. K. Jain, and G. B. Raupp, in "Tungsten and Other Advanced Metals for VLSI/ULSI Applications V," S. S. Wong and S. Furukawa, Editors, p. 179, The Materials Research Society, Pittsburgh, PA (1990).

30. C. M. McConica, J. K. Hunter, K. Tan, and M. D. Szczepaniak, in "Tungsten and Other Refractory Metals for VLSI Applications III," V. Wells, Editor, p. 47, The Materials Research Society, Pittsburgh, PA (1988).

31. W. A. Bryant, This Journal, 125, 1534 (1978).

32. P. van der Putte, in "Tungsten and Other Refractory Metals for VLSI Applications II," E. Broadbent, Editor, p. 77, The Materials Research Society, Pittsburgh, PA (1987).

33. J. O. Carlsson and M. Boman, J. Vac. Sci. Technol. A, 3, 2298 (1985)

34. E. Kato and K. Itsumi, This Journal, 135, 3163 (1988).

35. C. M. McConica, in "Tungsten and Other Refractory Metals for VLSI Applications II," E. Broadbent, Editor, p. 51, The Materials Research Society, Pittsburgh, PA (1987).

36. C. M. McConica and S. Churchill, in "Tungsten and Other Refractory Metals for VLSI Applications III," V. Wells, Editor, p. 257, The Materials Research Soci- 
ety, Pittsburgh, PA (1988).

37. S. Chatterjee and C. M. McConica, This Journal, 137, $328(1990)$

38. T. Moriya, K. Yamada, Y. Tsunashima, S. Nakata, and M. Kashiwagi, in "Extended Abstracts 15th Conf. Solid State Dev. and Mat.," p. 225, Tokyo (1983).

39. D. W. Hess, K. F. Jensen, and T. J. Anderson, Rev. Chem. Eng., 3, 97 (1985).

40. K. F. Jensen, Chem. Eng. Sci., 42, 923 (1987)

41. C. R. Kleijn, Th.H. van der Meer, and C. J. Hoogendoorn, This Journal, 136, 3423 (1990).

42. J. I. Ulacia, S. Howell, H. Körner, and Ch. Werner, Appl. Surf. Sci., 38, 370 (1989).

43. T. J. Jasinski and M. R. Harshbarger, in "Tungsten and Other Refractory Metals for VLSI Applications IV," B. Blewer and C. M. McConica, Editors, p. 27, The Materials Research Society, Pittsburgh, PA (1989).

44. E. J. McInerney, P. Geraghty, and S. Kang, in "Tungsten and Other Advanced Metals for VLSI/ ULSI Applications V," S. S. Wong and S. Furukawa, Editors, p. 135, The Materials Research Society, Pittsburgh, PA (1990).

45. A. Hasper, C. R. Kleijn, J. Holleman, J. Middelhoek, and C. J. Hoogendoorn, Submitted to This Journal.

46. W. G. Breiland, M. E. Coltrin, and P. Ho, J. Appl. Phys.,
59, 3267 (1986).

47. R. A. Svehla, "Estimated Viscosities and Thermal Conductivities of Gases at High Temperatures," NASA Technical Report R-132 (1962).

48. R. B. Bird, W. E. Stewart, and E. N. Lightfood, "Transport Phenomena," p. 22, John Wiley and Sons, New York (1960).

49. l'Air Liquide, Division Scientifique, "Encyclopédie des Gaz," Elsevier Scientific Publishing Co., Amsterdam (1976).

50. J. O. Hirschfelder, C. F. Curtiss, and R. B. Bird, "Molecular Theory of Gases and Liquids," John Wiley and Sons, New York (1967).

51. S. V. Patankar, "Numerical Heat Transfer and Fluid Flow," McGraw-Hill Book Co., New York (1980).

52. M. Suzuki and M. Sato, This Journal, 132, 1684 (1985).

53. C. R. Kleijn and C. J. Hoogendoorn, Chem. Eng. Science, To be published.

54. G. B. Raupp, in "Tungsten and Other Refractory Metals for VLSI Applications III," V. Wells, Editor, p. 15, The Materials Research Society, Pittsburgh, PA (1988).

55. J. J. Carbery, "Chemical and Catalytic Reaction Engineering," pp. 208-227, McGraw-Hill Book Co., New York (1976).

\title{
Reliability Improvements of Dichromated Gelatin Color Filter for TFT-LCDs
}

\author{
Atsushi Endo, ${ }^{*}$ Etsuko Hirose, Tetsuo Sato, Susumu Otera, and Norito Chiba \\ Mitsubishi Electric Corporation, Materials and Electronic Devices Laboratory, Amagasaki, Hyogo 661, Japan
}

\section{ABSTRACT}

Materials and processing technologies for a high quality color filter consisting of ammonium-dichromated gelatin (ADG) were studied. To achieve adequate characteristics of color reproducibility, the fixing process using tannic acid and potassium antimonyl tartrate and the thermal stability were investigated. The following results were attained: (i). It was clarified that the fixing process played two roles such as the strengthening of the binding force between gelatin and dye molecule, and prevention of a reaction between the remaining dyeing sites in gelatin and dye molecules. Careful control of the fixing process has improved the disappearance of discoloration of ADG patterns during the next dyeing process. (ii). The fading of the color layer was closely associated with the chemical structure of the dye. Anthraquinone dyes reduced the fading due to water absorption and heating of the film. Considering the above results, a reliable, reproducible, and high quality color filter for liquid crystal displays has been realized.

Photosensitive materials consisting of natural polymers such as gelatin with dichromate salts have long been used as negative resists in the graphic arts. They have recently found application in the fabrication of tricolor mosaics for optoelectronic devices because of their good photosensitivity, transparency, and dyeing properties. Ammoniumdichromated gelatin (ADG) films have been used as color filters for liquid crystal display devices $(1,2)$, and solidstate imaging devices (3-5).

Mosaics of color filters consisting of ADG and dye are capable of high resolution, good color reproducibility, and low manufacturing cost. There are two processes of color filters for electronics pertaining to color separation technologies between the different color layers. One is the stacked process using the color separator (passivation layer) as transparent polymer; this process is used for color solid-state imaging devices. The other is the fixing process using the fixing agents to prevent the cross contamination; this process is used for color liquid crystal display devices. The color filter obtained by the stacked process has the advantage of precisely controlled chromaticity characteristics, but it has the disadvantage of the difficulty of forming the flatness in achieving good electrical and color performance in the LCD structure. The color filter obtained by the fixing process has the advantages of the controllability of chromaticity characteristics and the flatness of the color layer.

* Electrochemical Society Active Member.
Regarding photosensitive polymers with dichromate as the photosensitive agent, the mechanism of cross-linking was investigated by Nice and Farley (6), Sasaki (7), and Duncalf and Dunn (8). These results suggested that hexavalent chromium was reduced to trivalent chromium by ultraviolet light (UV) exposure, and a three-dimensional network structure was built up with coordinate bonds between trivalent chromium and a lone pair of electrons in the polymer main chain. We studied (9) the relationship between the molecular weight and exposure characteristics of dichromated gelatin and found that the ADG film has a wide spectral sensitivity ranging from 220 to $510 \mathrm{~nm}$, and it is independent of the molecular weight of gelatin. Recently, the dyeing characteristics of ADG film were studied $(10)$, and the correlations of the trivalent chromium concentration and the dyeing property of ADG film were clarified.

The characteristics demanded of color filters applied to liquid crystal display devices concern factors of not only color reproducibility but also of materials and processing technologies. There have been few reported studies of the color filter, especially those obtained by the fixing process.

Therefore, we studied the fixing process successfully to attain a high quality color filter for liquid crystal display devices by evaluating the chromaticity characteristics of every process. This paper describes the important parameters for obtaining excellent color filters as well as the process technologies, and tries to make clear the fixing mech- 